COMMENT. The neurological syndrome of vitamin E deficiency is reviewed in an editorial by Dr HJ Kayden, Dept of Medicine, New York University Medical Center, New York ( Neurology Nov 1993; $\underline{43}$ :21672169). Abetalipoproteinemia and cholestatic liver disease are characterized by fat malabsorption, resulting in steatorrhea and vitamin E deficiency. In familial isolated vitamin E deficiency, lipid and vitamin $\mathrm{E}$ absorption and plasma lipoproteins are normal but conservation of plasma a-tocopherol is poor due to impaired secretion in very low-density lipoproteins. Patients must maintain continuous supplementation with vitamin E (600 IU twice daily, $5-10 \mathrm{mg} / \mathrm{kg}$ ).

The observation that some patients with typical signs of Friedreich's ataxia have a familial vitamin E deficiency syndrome emphasizes the recommendation that all patients with ataxia and neuropathy should have plasma vitamin E determinations. Early supplementation with vitamin E should halt progression of ataxia, and genetic linkage analysis may establish the diagnosis. Asymptomatic sibs should be tested in early childhood, since vitamin E may prevent the onset of ataxia in those affected.

\title{
CHOROIDO-CEREBRAL CALCIFICATION WITH RETARDATION
}

A family of three children with mental retardation, calcification of the choroid plexus, and increased CSF protein is reported from the Riyadh Armed Forces Hospital, and Maternity and Children's Hospital, Riyadh, Saudi Arabia. A 7-year-old Saudi girl born to nonconsanguinous parents showed delayed development. She sat at 3 years, walked at 5, and spoke two- to three-word phrases at 7 years of age. An 8-year-old brother and 5-year-old-sister were similarly affected. Skull radiographs, CT, and MRI showed calcifications along the distribution of choroid plexuses of the lateral ventricles, and calcification involving the caudate nucleus and septum pellucidum. In one child, these findings at 1 year were unchanged over the next 7 years. CSF protein was 180 $\mathrm{mg} / \mathrm{dl}$, while phosphate levels in the CSF were low, with a CSF/serum ratio of 0.25 cf normal of 0.73 . (Singh B et al. Choroido-cerebral calcification syndrome with retardation. Neurology Nov 1993; $\underline{43}: 2387-2389)$. (Reprints: Dr B Singh, Div Ped Neurology, Southwestern Medical School, 5323 Harry Hines Blvd, Dallas, TX 75235).

COMMENT. Two previous reports of a family of 6 children with a similar syndrome are cited. An autopsy on one patient had shown multiple small subcortical heterotopias and adrenal atrophy (Lott IT et al. Familial amentia, unusual ventricular calcifications, and increased cerebrospinal fluid protein. Neurology 1979;29:1571). That phosphate metabolism may be involved in the pathogenesis is suggested by Singh and co-authors. 